Diana Alexandra González-Tenemaza; Marcos Patricio Quinteros-Cortzar; Ana Luisa del Rocio Ordoñez-Laso; Mireya Magdalena Torres-Palacios

http://dx.doi.org/10.35381/r.k.v5i3.908

\title{
Productividad laboral en la Dirección Distrital del Ministerio de Transporte y Obras Públicas del Cañar
}

\section{Productivity in the District Office of de Ministry of Transport and Public Works of Cañar}

\author{
Diana Alexandra González-Tenemaza \\ diana.gonzalez.98@psg.ucacue.edu.ec \\ Universidad Católica de Cuenca, Cuenca \\ Ecuador \\ https://orcid.org/0000-0003-3829-086X \\ Marcos Patricio Quinteros-Cortzar \\ mpquinterosc@ucacue.edu.ec \\ Universidad Católica de Cuenca, Cuenca \\ Ecuador \\ https://orcid.org/0000-0003-2755-5041 \\ Ana Luisa del Rocío Ordoñez-Laso \\ alordonesl@ucacue.edu.ec \\ Universidad Católica de Cuenca, Cuenca \\ Ecuador \\ https://orcid.org/0000-0002-7935-6709 \\ Mireya Magdalena Torres-Palacios \\ mireya.torres@ucacue.edu.ec \\ Universidad Católica de Cuenca, Cuenca \\ Ecuador \\ https://orcid.org/0000-0002-7724-3313
}

Recibido: 20 de mayo de 2020

Revisado: 15 de junio de 2020

Aprobado: 30 de julio de 2020

Publicado: 15 de agosto de 2020 
Diana Alexandra González-Tenemaza; Marcos Patricio Quinteros-Cortzar; Ana Luisa del Rocio Ordoñez-Laso; Mireya Magdalena Torres-Palacios

\title{
RESUMEN
}

La investigación tuvo por objetivo analizar la productividad laboral en la Dirección Distrital del Ministerio de Transporte y Obras Públicas del Cañar - Ecuador. Metodológicamente se basó en un tipo descriptiva con diseño no experimental de campo, siendo el universo poblacional constituido por la totalidad de servidores y trabajadores de la Dirección Distrital del Ministerio de Transporte y Obras Públicas del Cañar, es decir 61 personas que se encuentran prestando sus servicios en la institución. La innovación de los recursos disponibles mediante la implementación de nueva tecnología, sistematización de los procesos y constante capacitación de los servidores fortalecen la satisfacción de los usuarios y la imagen institucional a través del tiempo. La herramienta diseñada es fundamental para medir si el desempeño de los servidores públicos está acorde a las planificaciones departamentales, sus resultados pueden ser presentados a través de informes a los niveles directivos.

Descriptores: Recursos humanos; desarrollo de recursos humanos; productividad; crecimiento económico. (Palabras tomadas del Tesauro UNESCO).

\begin{abstract}
The objective of the research was to analyze labor productivity in the District Directorate of the Ministry of Transport and Public Works of Cañar - Ecuador. Methodologically it was based on a descriptive type with non-experimental field design, the population universe being made up of all the servers and workers of the District Directorate of the Ministry of Transport and Public Works of Cañar, that is, 61 people who are providing their services In the institution. The innovation of available resources through the implementation of new technology, systematization of processes and constant training of the servers strengthen user satisfaction and institutional image over time. The designed tool is essential to measure whether the performance of public servants is in accordance with departmental planning, its results can be presented through reports to management levels.
\end{abstract}

Descriptors: Human resources; human resources development; productivity; economic growth. (Words taken from the UNESCO Thesaurus). 
Diana Alexandra González-Tenemaza; Marcos Patricio Quinteros-Cortzar; Ana Luisa del Rocio Ordoñez-Laso; Mireya Magdalena Torres-Palacios

\section{INTRODUCCIÓN}

El 9 de julio de 1929, se estableció como institución, el Ministerio de Obras Públicas y Comunicaciones (MOP) (Ministerio de Transporte y Obras Públicas del Ecuador, 2017), cuyo objetivo principal fue el de ejecutar obras viales y de comunicaciones dentro del país, es decir, los estudios, construcción, explotación, conservación y financiamiento de las obras públicas. Adicionalmente en sus inicios además de contar con la Dirección General de Obras Públicas, tuvo a su cargo las Direcciones de Agricultura, Correos y Telégrafos. Dentro de sus funciones se incluyeron la fiscalización de las obras ejecutadas por contrato, así como el estudio de reformas de legislación en temas relacionados con el agro, el agua y los bosques.

Posteriormente, en el año 1992 el MOP instituyó el departamento de Impactos Ambientales, con la finalidad de vigilar el uso de materiales nocivos utilizados en la construcción y rehabilitación de carreteras de la red estatal en las áreas de influencia directa e indirecta, identificando los potenciales impactos biofísicos y socio-culturales que podrían causar las obras realizadas en la comunidad.

El 15 de enero de 2007, mediante Decreto Ejecutivo 8, se cambió la estructura y se creó el Ministerio de Transporte y Obras Públicas (MTOP) constituido por cuatro subsecretarías: de Transporte Vial y Ferroviario, de Puertos y Transporte Marítimo y Fluvial, de Aeropuertos y Transporte Aéreo, y de Obras Públicas y Comunicaciones. (Registro Oficial 18 de 08-feb-2007).

Actualmente el MTOP, cuenta con dos Viceministerios y 7 Subsecretarías Zonales que abarcan las 24 Direcciones Distritales con jurisdicción en el ámbito de cada provincia. La Subsecretaria Zonal 6 abarca las Provincias de Cañar, Azuay y Morona Santiago. El objeto de estudio de esta investigación es la Dirección Distrital del Ministerio de Transporte y Obras Públicas del Cañar, ubicada en la Ciudad de Azogues en las calles Augusto Sacoto y General Enríquez, cuyas funciones se enfocan a procesos sustantivos como Gestión Interna de la Infraestructura Distrital del Transporte, Gestión Interna de Conservación de la Infraestructura Distrital de Transporte y Gestión interna del Transporte Distrital en la provincia del Cañar; de igual 


\section{Diana Alexandra González-Tenemaza; Marcos Patricio Quinteros-Cortzar;} Ana Luisa del Rocio Ordoñez-Laso; Mireya Magdalena Torres-Palacios

manera procesos adjetivos de Gestión Interna Administrativa-Financiera. Actualmente la institución cuenta con 61 colaboradores entre servidores y trabajadores públicos. El presente estudio estará dirigido a evaluar la productividad laboral de los colaboradores de la Dirección Distrital del Ministerio de Transporte y Obras Públicas del Cañar; debido a que se han identificado deficiencias en los procesos administrativos como: retraso en trámites internos y externos, baja productividad laboral, bajo conocimiento en paquetes informáticos, falta de actualización de conocimientos, falta de supervisión en los procesos. Sumándose a estas causas el bajo aporte y falta de compromiso de algunos colaboradores, creando insatisfacción en los usuarios y el incumplimiento o cumplimiento tardío del trabajo asignado.

\section{Referencial teórico}

\section{El rol del Capital Intelectual en las organizaciones}

Para entender el papel del capital intelectual, se compara a la organización con la estructura de un árbol, dividiéndolo en una parte visible que incluyen las hojas, ramas y frutos; y, otra invisible, las raíces; si solamente nos interesamos en mantener en buen estado la parte visible del árbol y recoger sus frutos, descuidando sus raíces, el árbol puede morir. Algo similar sucedería en la organización si ponemos énfasis solamente en la cantidad de producción y los resultados financieros, y no en su estructura interna (capital intelectual), por cuanto podría llegar un momento en el que su estructura se desestabilice y fracase (Villegas-González, et al., 2017).

Para (Bustos-Farías, et al., 2016), lo que generalmente promueve y motiva el cambio en las organizaciones es su necesidad de adaptarse a las variaciones del mercado, de satisfacer las demandas sociales, mejorar la calidad de sus productos, ajustarse a las normas internacionales, permitiendo lograr proyectos más estables y duraderos en el tiempo. Esta estabilidad se desarrolla con más facilidad y es más visible en organizaciones cuyas actividades comerciales están orientadas al conocimiento que cuentan con amplios departamentos de ingeniería, así como también en gobiernos de países desarrollados; siendo por el contrario menos visible para las economías menos 


\section{Diana Alexandra González-Tenemaza; Marcos Patricio Quinteros-Cortzar;} Ana Luisa del Rocio Ordoñez-Laso; Mireya Magdalena Torres-Palacios

desarrolladas como las de Latinoamérica y que son adoptadas habitualmente en la mayoría de las micro empresas, pequeñas empresas, medianas empresas.

El concepto de capital intelectual ha ido evolucionando gracias a las diversas aportaciones que coinciden que el conocimiento se convierte en la máquina de producción más potente y que aporta al crecimiento del valor de mercado y valor contable de las organizaciones. (Galleguillos-Cortés et al., 2018). En la actualidad el $\mathrm{Cl}$ es aprovechado por las empresas y organizaciones para reducir los ciclos de vida de los productos y servicios. Sin embargo, para que se produzca $\mathrm{Cl}$ tiene que existir la combinación de un componente activo que abarca los conocimientos, competencias y aptitudes, llamado activo intelectual y un componente pasivo que son los productos que se generan a partir del componente activo y que se convierten en patrimonio cultural o propiedad intelectual de la organización (Erazo \& Narváez, 2020). Mientras este patrimonio cultural no sea transmitido, aplicado y genere valor en la organización no operará como capital intelectual (Monagas-Docasal, 2012).

Por otro lado, (González-Millán \& Rodriguez-Díaz, 2016) afirman que el valor del capital intelectual se concentra en aquellos colaboradores que aportan con su trabajo a mejorar los procesos de la organización, mediante la innovación, el incremento de sus rendimientos y la reducción de costos. De esta manera se puede concluir que se considera al talento humano como la base de la organización que, a través de sus habilidades, destrezas, aptitudes, capacidad de solucionar problemas, preparación académica y profesional aportan al perfeccionamiento y crecimiento de la productividad, así como a establecer estándares de calidad de los productos o servicios. Creando así una ventaja competitiva en el mercado y añadiendo un valor agregado a la organización, este talento humano altamente desarrollado, pasaría a formar parte del capital intelectual de la organización.

En un futuro muchos empleos demandarán habilidades específicas, como discernimientos tecnológicos, facultad para resolver conflictos y pensamiento crítico; así como también requerirán de habilidades blandas, como por ejemplo la perseverancia, la cooperación y la empatía. En este sentido es importante que los países que se encuentran en vías de desarrollo consideren invertir esencialmente en 


\section{Diana Alexandra González-Tenemaza; Marcos Patricio Quinteros-Cortzar;} Ana Luisa del Rocio Ordoñez-Laso; Mireya Magdalena Torres-Palacios

salud y educación, como base del Capital Intelectual, aprovechando el recurso tecnológico disponible y adoptando medidas correctivas que les permitan competir en la economía del futuro, debido al acelerado ritmo de la innovación (Contreras, et al., 2015).

Es evidente que el valor del capital intelectual $(\mathrm{Cl})$ es de suma importancia para determinar el valor real de una empresa, por cuanto puede superar en tres o cuatro veces el valor de los activos tangibles según el sector al que la empresa pertenezca (Arias-Pérez, 2019) constituye un activo intangible no transferible que puede capitalizar las experiencias y convertir el conocimiento en ventaja competitiva y dado que las medidas financieras no son suficientes para la toma de decisiones, es indiscutible la importancia de medir y gestionar estos activos en las instituciones (Villegas-González, et al., 2017). De acuerdo con lo expuesto, hay que destacar que la medición del capital intelectual ofrece juicios de valor para la gestión de las organizaciones, mediante el uso de indicadores que permiten conocer la situación actual, identificar problemas y oportunidades; además tomar las acciones correctivas a través de la generación de información que puede ser utilizada por sus propietarios o accionistas en la toma de decisiones.

\section{El Modelo Intellectus como herramienta de identificación y medición de los}

\section{Activos Intangibles}

Para la realización de esta publicación se ha optado por un análisis y selección el modelo Intellectus de Medición y Gestión del capital intelectual, que es una versión actualizada del modelo desarrollado por Eduardo Bueno Campos (Bueno \& CIC, 2003), debido a su aplicación fácil y práctica. El modelo Intellectus se basa en las siguientes características:

1. Armónico: Presenta una distribución interrelacionada y completa de sus componentes.

2. Abierto: Muestra una estructura que se relaciona entre si a pesar de las diferencias en la naturaleza de los agentes del conocimiento que forman parte de la organización. 
Diana Alexandra González-Tenemaza; Marcos Patricio Quinteros-Cortzar; Ana Luisa del Rocio Ordoñez-Laso; Mireya Magdalena Torres-Palacios

3. Flexible: Permite una elección diferenciada de sus elementos y variables, ya que pueden ser aplicados acorde a las necesidades de cada institución.

4. Adaptable: Se adecúa de tal manera que cada institución o empresa pueda ajustar la propuesta según lo requiera.

5. Dinámico: Ofrece una estructura de "árbol de pertinencia" a partir de sus componentes, elementos, variables y relaciones.

Por otro lado, (Bueno, et al., 2011) indica que el modelo Intellectus considera que el capital intelectual se encuentra conformado por los siguientes componentes:

1. El Capital Humano compuesto por el conocimiento, los valores, las aptitudes y la capacidad de las personas que forman parte de una organización, mismos que se ven reflejados en su producción y que a partir de su nivel de preparación y perfil profesional comparten sus conocimientos a los demás miembros beneficiando a la institución.

2. El Capital Estructural que se refiere a los conocimientos propios de la institución, y que permanecen en ella aun cuando sus colaboradores dejan de prestar sus servicios, este a su vez se encuentra dividido en capital tecnológico y capital organizativo.

3. El Capital Relacional que es el acumulado de conocimientos derivados de las relaciones que mantiene la organización con la sociedad y agentes del mercado, y que permite incluso formar alianzas entre organizaciones. El Capital Relacional se subdivide en Capital de Negocio y en Capital Social (ErazoÁlvarez \& Narváez-Zurita, 2020).

4. El Capital de Emprendimiento e Innovación que se encuentra compuesto por los resultados de implementar innovación, la inversión en innovación y la capacidad de emprender. 
Diana Alexandra González-Tenemaza; Marcos Patricio Quinteros-Cortzar; Ana Luisa del Rocio Ordoñez-Laso; Mireya Magdalena Torres-Palacios

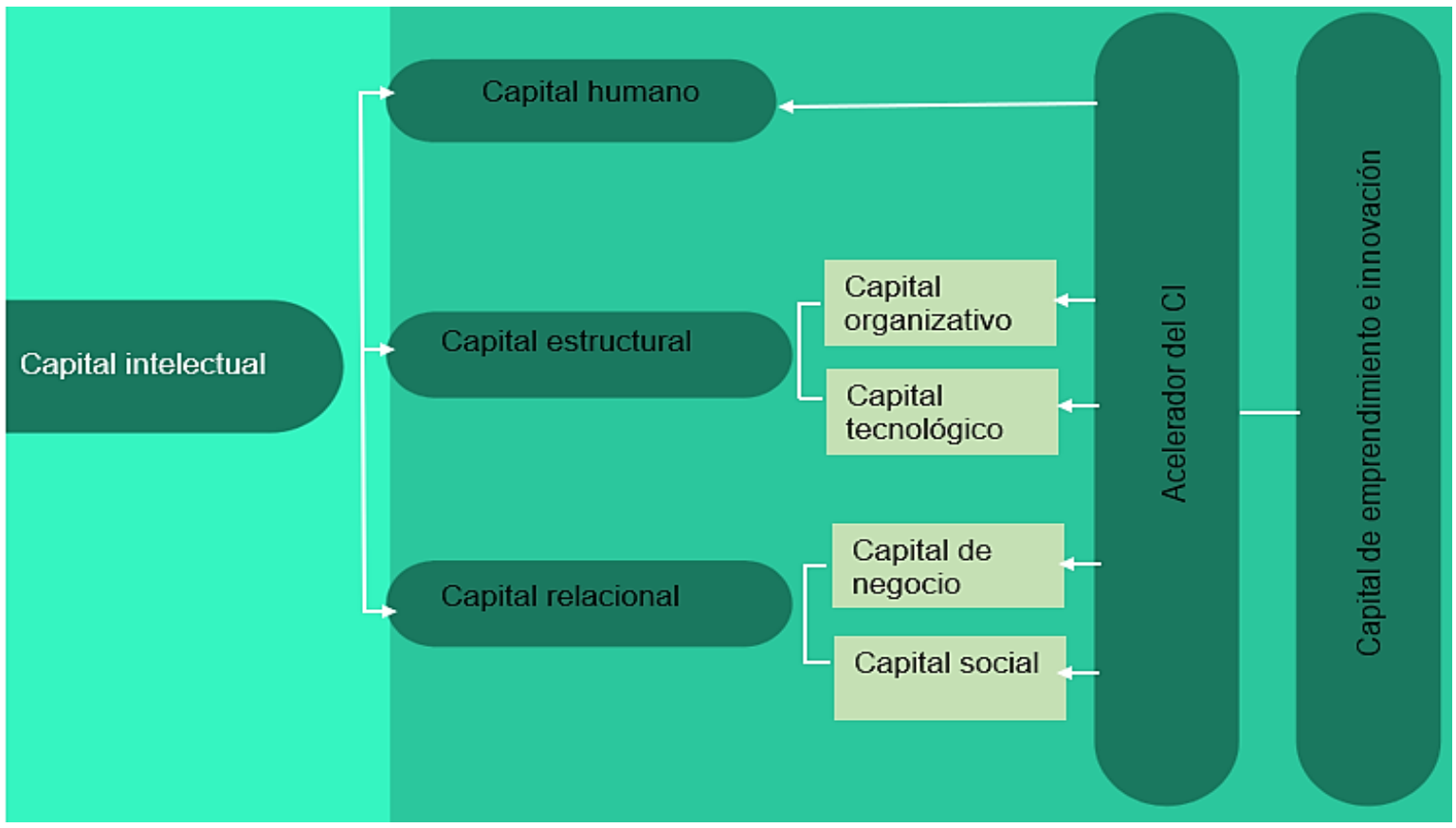

Figura 1. Estructura y componentes del Modelo Intellectus. Fuente: Bueno (2011).

Cada capital que integra el capital intelectual en el modelo Intellectus, se encuentra compuesto por varios elementos y variables que se detallan en la siguiente tabla:

\section{Tabla 1.}

Elementos y variables del modelo Intellectus.

\begin{tabular}{|c|c|c|}
\hline Capital & Elementos & Variables \\
\hline \multirow[t]{3}{*}{ Humano } & Valores y actitudes & $\begin{array}{l}\text { Comprende variables como el compromiso, } \\
\text { motivación, satisfacción, socialización y } \\
\text { orientación al cliente, flexibilidad y creatividad. }\end{array}$ \\
\hline & Aptitudes & $\begin{array}{l}\text { Se incluye la instrucción formal, formación } \\
\text { profesional, formación interna, y superación } \\
\text { personal. }\end{array}$ \\
\hline & Capacidades & $\begin{array}{l}\text { Abarca el liderazgo, el aprendizaje, el trabajo } \\
\text { en equipo, la transmisión de conocimientos, el } \\
\text { equilibrio entre la vida familiar y laboral. }\end{array}$ \\
\hline \multirow[t]{3}{*}{ Organizativo } & Cultura & $\begin{array}{l}\text { Define la uniformidad cultural, desarrollo de } \\
\text { valores culturales, clima laboral y social, } \\
\text { filosofía de negocio, identidad organizacional, } \\
\text { y sensibilidad de género. }\end{array}$ \\
\hline & $\begin{array}{l}\text { Estructura } \\
\text { Aprendizaje organizativo }\end{array}$ & $\begin{array}{l}\text { Implica el diseño y desarrollo organizativo. } \\
\text { Se refiere a los ambientes de abrendizaie en }\end{array}$ \\
\hline & & $\begin{array}{l}\text { donde se crea, desarrolla y transmite el } \\
\text { conocimiento. }\end{array}$ \\
\hline
\end{tabular}


Diana Alexandra González-Tenemaza; Marcos Patricio Quinteros-Cortzar; Ana Luisa del Rocio Ordoñez-Laso; Mireya Magdalena Torres-Palacios

Procesos

Incluye los procesos dirigidos a clientes internos y externos, así como a los proveedores.

Capital Esfuerzo en Investigación más
Comprende los gastos en personal y tecnológico desarrollo proyectos destinados a investigación y desarrollo.

Dotación tecnológica

Se refiere a la inversión en tecnología para la producción y comunicaciones.

Propiedad Intelectual e industrial Conformado por patentes, marcas, licencias y dominios.

Vigilancia tecnológica

Información sobre patentes, actividad tecnológica de la competencia, líneas de investigación, posibles asociaciones con empresas para investigación y desarrollo, localización de tecnologías que requieren licencias.

De Negocio Relación con los clientes.

Relación con proveedores

Relación con accionistas e instituciones

Relación con aliados

Relación con competidores

Relación con instituciones de promoción y la calidad Relación con empleados

$\begin{array}{lll}\text { Capital Social } & \text { Relaciones con las } \\ & \text { Administraciones Públicas } \\ & \text { Relaciones con medios de } \\ & \text { comunicación e imagen } \\ & \text { empresarial } \\ & \text { Relaciones con la defensa del } \\ & \text { medio ambiente } \\ & \text { Relaciones Sociales }\end{array}$

Reputación corporativa

emprendimiento

Esfuerzo en Innovación

Actitud y emprendimiento
Contiene la base de datos sobre la fidelización, satisfacción del cliente y redes de distribución.

Se refiere a las relaciones formales con proveedores, soporte tecnológico, personalización del bien o servicio y capacidad de respuesta.

Compuesto por las relaciones con accionistas, inversores, instituciones, empresas.

Define las alianzas y sus beneficios

Abarca la relación y conocimiento de los competidores

Implica las relaciones con entidades de calidad y sus certificaciones

Involucra la relación, satisfacción y fidelización de los empleados.

Define la colaboración y participación en la gestión pública.

Implica el reconocimiento de la marca y las relaciones con medios de comunicación.

Cumplimiento de normas y relación con entidades ambientales.

Relación con sindicatos e instituciones del mercado laboral.

Comprende códigos de conducta, de gobierno, de igualdad y conciliación del entorno familiar y profesional.

Integra la innovación en valores, gestión, tecnológica, social y responsabilidad social de las entidades.

Corresponde a la inversión en personal y proyectos de innovación.

Abarca la actitud, aptitud y creatividad para emprender.

Fuente: Bueno (2011). 


\section{Diana Alexandra González-Tenemaza; Marcos Patricio Quinteros-Cortzar;} Ana Luisa del Rocio Ordoñez-Laso; Mireya Magdalena Torres-Palacios

Cada variable antes descrita posee indicadores que sirven de guía y deben ser ajustados de acuerdo con las necesidades de la organización. Luego de elegir los indicadores, elementos, variables, se construye un índice sintético, mediante la asignación de ponderaciones a los indicadores, ordenando los elementos de manera jerárquica en tantos niveles como se desee y asignando valores numéricos (del 1 al 9). El procedimiento de medición se aplica enfrentando por parejas los indicadores de criterio similar, hasta terminar de emparejar los indicadores de todos los niveles que componen el modelo.

Tabla 2.

Valor de los indicadores por parejas.

\begin{tabular}{lll}
\hline Intensidad & Significado & Análisis \\
\hline 1 & Importancia semejante & $\begin{array}{l}\text { Los dos juicios aportan igual } \\
\text { valoración. }\end{array}$ \\
3 & Importancia moderada. & $\begin{array}{l}\text { Se inclina a favor de uno de } \\
\text { ellos. }\end{array}$ \\
5 & Fuerte importancia. & $\begin{array}{l}\text { Se inclina mayormente a } \\
\text { favor de uno de ellos } \\
\end{array}$ \\
7 & Muy fuerte importancia. & (De forma análoga). \\
9 & Extremadamente importante. &
\end{tabular}

Fuente: Bueno (2011).

Los valores fijados en el índice sintético establecen la unidad de criterio que servirá para medir los elementos del $\mathrm{Cl}$, medida que tomará el nombre de "intelto" o evaluación del capital intangible desarrollado dentro de los procesos de la organización (Erazo-Álvarez \& Narváez-Zurita, 2020).

Finalmente, se genera un informe que cumpla con los siguientes objetivos: informar cómo se desarrolló el proceso de identificación de activos intangibles, presentar los indicadores elegidos para construir el índice sintético, informar el contenido del modelo de $\mathrm{Cl}$ y facilitar una guía para mejorar la gestión de los activos intangibles. El informe debe estar estructurado de la siguiente manera:

1.- Introducción y presentación de la organización.

2.- Modelo de $\mathrm{Cl}$.

3.- Resultados del Informe: medición del Cl. 
Diana Alexandra González-Tenemaza; Marcos Patricio Quinteros-Cortzar; Ana Luisa del Rocio Ordoñez-Laso; Mireya Magdalena Torres-Palacios

4.- Conclusiones y recomendaciones.

\section{La productividad laboral y su aporte a la gestión pública}

La productividad es el arte de crear, mejorar y optimizar un bien o servicio, implica relacionar las entradas y las salidas empleadas en el proceso de producción, refiriéndose a salidas como lo que se ha producido y a entradas como todo lo que se ha utilizado para producir los bienes o servicios, la diferencia será el ingreso generado en el proceso productivo, en esencia la productividad mide la eficiencia en el uso de los recursos disponibles (Cid, et al., 2016). En la actualidad, existe preocupación en las organizaciones para incrementar la productividad y ser más competitivas, este incremento se puede lograr organizando y gestionando adecuadamente los procesos que intervienen en la producción de bienes y servicios, prestando atención a los tres clientes claves de la empresa: el cliente final, la sociedad y sus trabajadores. Entre las metodologías utilizadas para volver competitivas a las organizaciones se encuentra inculcar la participación de todo el personal en los objetivos fundamentales de la organización, la colaboración del personal en los diferentes procesos motivando su capacitación, conocimiento y creatividad, contribuyendo así a obtener estándares más altos de calidad y productividad (Kato, 2019).

La gestión del rendimiento es el conjunto de herramientas que se utilizan para mejorar el éxito de los miembros de la organización permitiéndoles desarrollar la habilidad de tomar decisiones, asegurando que el trabajo de cada empleado contribuya a lograr los objetivos y la productividad planteada. Una adecuada gestión documentada del rendimiento permite identificar problemas al instante, tomar decisiones adecuadas, resolverlos de manera oportuna y reducir la necesidad de controlar de forma cercana al personal y por ende la aplicación de métodos disciplinarios, ofrece además una constancia para que la organización se proteja en caso de demandas (Chiang-Vega \& Ojeda-Hidalgo, 2013).

Para (Robledillo-Colmenares \& Velázquez-López, 2013), la calidad total que conduce a incrementar la productividad y competitividad de las organizaciones, no se logra solamente con el cumplimiento e implementación de normas y especificaciones de 


\section{Diana Alexandra González-Tenemaza; Marcos Patricio Quinteros-Cortzar;} Ana Luisa del Rocio Ordoñez-Laso; Mireya Magdalena Torres-Palacios

calidad, sino que es el resultado del cambio en la cultura de las organizaciones. La cultura incluye el conjunto de elementos materiales e inmateriales que definen la identidad de la empresa y la diferencian de otros grupos humanos, entre ellos la misión, los valores, las actitudes, y los comportamientos de los miembros que integran la organización.

La calidad de vida de los habitantes de un país, depende de la habilidad de sus empresas para producir bienes y servicios con alta productividad, mediante la inversión en investigación y desarrollo, incrementando el ingreso per cápita y el producto interno bruto, incidiendo como motor de desarrollo en la macro economía del país. (Van-den-Berghe, 2015).

La Ley Orgánica de Servicio Público LOSEP (Registro Oficial Suplemento 294 de 06oct.-2010) que regula la administración del talento humano en el sector público del Ecuador, tiene por objetivo promover el crecimiento profesional y personal de los servidores públicos con la finalidad de mejorar la productividad de las instituciones estatales de manera permanente, mediante una gestión adecuada del talento humano, sin discriminación alguna, basado en el respeto de sus derechos y la igualdad de oportunidades (Reyes, et al., 2020). Sin embargo, resulta difícil medir la productividad de los servidores del sector público que ejecutan actividades administrativas, ya que no existe un buen indicador de su producción que suministre pruebas concluyentes sobre la eficiencia del Estado (Castelao-Caruana, 2016), mientras que (Pliscoff-Varas, 2017), plantea que el rendimiento de las actividades en la gestión pública, sin importar si el giro es de índole tributaria, regulativa, de bienestar o producción de servicios públicos, puede ser analizada mediante indicadores críticos de la gerencia.

Desde lo planteado, la investigación tuvo por objetivo analizar la productividad laboral en la Dirección Distrital del Ministerio de Transporte y Obras Públicas del Cañar Ecuador. 


\section{Diana Alexandra González-Tenemaza; Marcos Patricio Quinteros-Cortzar} Ana Luisa del Rocio Ordoñez-Laso; Mireya Magdalena Torres-Palacios

\section{MÉTODO}

La metodología se basó en un tipo descriptiva con diseño no experimental de campo, siendo el universo poblacional constituido por la totalidad de servidores y trabajadores de la Dirección Distrital del Ministerio de Transporte y Obras Públicas del Cañar, es decir 61 personas que se encuentran prestando sus servicios en la institución, tanto del área administrativa, el área técnica, de conservación vial (Bernal, 2010), aplicándose encuesta y cuestionario en escala Likert de cinco alternativas de respuestas siendo validado por juicio de expertos y calculo de coeficiente de Alfa de Cronbach de 0,89 siendo catalogada como confiable para su aplicación, la cual fue dosifcada vía online, analizándose los datos recopilados mediante estadistica descriptva (Rodríguez, et al., 2019).

\section{RESULTADOS}

Los resultados obtenidos luego de la aplicación de los instrumentos de investigación a los servidores de la Dirección Distrital del Ministerio de Transporte y Obras Públicas del Cañar, se presentan de manera gráfica a continuación:

\section{Tabla 3.}

Resultado en porcentaje, opción múltiple a encuesta aplicada.

\begin{tabular}{|c|c|c|c|c|c|c|c|}
\hline Dimensiones & Preguntas & $\begin{array}{l}\text { Totalmente } \\
\text { de acuerdo }\end{array}$ & $\begin{array}{l}\text { De } \\
\text { acuerdo }\end{array}$ & Indeciso & $\begin{array}{l}\text { En } \\
\text { desacuerdo }\end{array}$ & $\begin{array}{l}\text { Totalmente } \\
\text { en } \\
\text { desacuerdo }\end{array}$ & Total \\
\hline \multirow[t]{3}{*}{$\begin{array}{l}\text { Capital } \\
\text { Humano }\end{array}$} & $\begin{array}{l}\text { ¿En la institución se } \\
\text { considera importante } \\
\text { la formación } \\
\text { académica de los } \\
\text { servidores? }\end{array}$ & 13,11 & 50,82 & 11,48 & 14,75 & 9,84 & 100 \\
\hline & $\begin{array}{l}\text { ¿Los conocimientos } \\
\text { adquiridos en los } \\
\text { cursos de } \\
\text { capacitación se } \\
\text { aplican de manera } \\
\text { óptima en su puesto } \\
\text { de trabajo? }\end{array}$ & 9,84 & 44,26 & 18,03 & 24,59 & 3,28 & 100 \\
\hline & $\begin{array}{l}\text { ¿Considera Usted, } \\
\text { que en la institución } \\
\text { las experiencias tanto } \\
\text { positivas como } \\
\text { negativas, son } \\
\text { utilizadas como una }\end{array}$ & 19,67 & 54,10 & 4,92 & 19,67 & la & 100 \\
\hline
\end{tabular}


Diana Alexandra González-Tenemaza; Marcos Patricio Quinteros-Cortzar; Ana Luisa del Rocio Ordoñez-Laso; Mireya Magdalena Torres-Palacios

fuente de aprendizaje?

\begin{abstract}
¿Posee los
conocimientos

adecuados para

desempeñarse en el

puesto que

actualmente ocupa?

¿Efectúa aportes de

carácter académico o

técnico que sirvan de

beneficio a su unidad de trabajo?
\end{abstract}

$50,82 \quad 45,90$

1,64

0,00

$1,64 \quad 100$

24,59

19,67

6,56

$3,28 \quad 100$

\begin{tabular}{|c|c|c|c|c|c|c|c|}
\hline \multirow[t]{5}{*}{$\begin{array}{l}\text { Capital } \\
\text { Estructural }\end{array}$} & $\begin{array}{l}\text { ¿La institución evalúa } \\
\text { al personal, y realiza } \\
\text { el proceso de } \\
\text { retroalimentación } \\
\text { para corregir } \\
\text { situaciones que } \\
\text { afectan el desempeño } \\
\text { laboral? }\end{array}$ & 6,56 & 34,43 & 19,67 & 29,51 & 9,84 & 100 \\
\hline & $\begin{array}{l}\text { ¿La distribución física } \\
\text { del ambiente de } \\
\text { trabajo facilita la } \\
\text { realización adecuada } \\
\text { de sus labores } \\
\text { diarias? }\end{array}$ & 18,03 & 59,02 & 11,48 & 9,84 & 1,64 & 100 \\
\hline & $\begin{array}{l}\text { ¿Consulta e investiga } \\
\text { manuales que tengan } \\
\text { relación con su } \\
\text { trabajo? }\end{array}$ & 50,82 & 31,15 & 6,56 & 8,20 & 3,28 & 100 \\
\hline & $\begin{array}{l}\text { ¿El ambiente creado } \\
\text { por sus compañeros } \\
\text { es el ideal para } \\
\text { desempeñar sus } \\
\text { funciones? }\end{array}$ & 8,20 & 49,18 & 18,03 & 22,95 & 1,64 & 100 \\
\hline & $\begin{array}{l}\text { ¿Se siente } \\
\text { identificado con sus } \\
\text { funciones y están } \\
\text { acorde al cargo que } \\
\text { ocupa dentro de la } \\
\text { institución? }\end{array}$ & 39,34 & 37,70 & 6,56 & 13,11 & 3,28 & 100 \\
\hline $\begin{array}{l}\text { Capital } \\
\text { Relacional }\end{array}$ & $\begin{array}{l}\text { ¿El tipo de servicio } \\
\text { que se brinda a los } \\
\text { usuarios afecta la } \\
\text { imagen de la } \\
\text { institución? }\end{array}$ & 45,90 & 45,90 & 4,92 & 1,64 & 1,64 & 100 \\
\hline
\end{tabular}

Fuente: Encuesta aplicada. 


\section{Diana Alexandra González-Tenemaza; Marcos Patricio Quinteros-Cortzar;} Ana Luisa del Rocio Ordoñez-Laso; Mireya Magdalena Torres-Palacios

\section{Capital humano}

De las preguntas planteadas en relación al capital humano el 9,84\% de los empleados está en desacuerdo que la institución considera importante la formación académica de los servidores, el $14,75 \%$ totalmente en desacuerdo y el $11,48 \%$ indeciso, el $50,82 \%$ de acuerdo y el 13,11 totalmente de acuerdo, siendo importante analizar el nivel de estudios con el que cuentan los servidores públicos y el aporte que pueden brindar para mejorar los procesos tanto en el área administrativa como en el área técnica. Si bien el 50,82\% de los colaboradores están totalmente de acuerdo y el $45,90 \%$ de acuerdo en que posee los conocimientos adecuados para desempeñar el puesto que actualmente ocupa, y solamente se tiene un porcentaje del 1,64\% que está totalmente en desacuerdo, se debe poner atención en que el 3,28\% está totalmente en desacuerdo, el $24,59 \%$ están en totalmente en desacuerdo, el 18,03\% indeciso , el $44,26 \%$ de acuerdo y el $9,84 \%$ totalmente de acuerdo en que los cursos de capacitación se aplican de manera óptima en su puesto de trabajo siendo fundamental revisar los planes de capacitación y su aplicación óptima a las actividades laborales diarias.

\section{Capital estructural}

Solamente el $49,8 \%$ y el $8,20 \%$ están de acuerdo y totalmente de acuerdo respectivamente en que el ambiente creado por los compañeros es ideal para desempeñar sus funciones, el 18\% fue indiferente, el 22,95\% está en desacuerdo y el $1,64 \%$ totalmente en desacuerdo, existiendo tal vez un aspecto que involucra que las actividades no se desarrollen normalmente y por ende se puede ver reflejado en servicio deficiente al usuario externo.

\section{Capital relacional}

El 45,90\% está de acuerdo y totalmente de acuerdo que el tipo de servicio que se brinda a los usuarios afecta la imagen de la institución, el 4,92\% indeciso y el 1,64\% en desacuerdo y totalmente en desacuerdo; siendo importante que la Dirección Distrital del Ministerio de transporte y Obras Públicas aproveche este particular para 


\section{Diana Alexandra González-Tenemaza; Marcos Patricio Quinteros-Cortzar;} Ana Luisa del Rocio Ordoñez-Laso; Mireya Magdalena Torres-Palacios

incentivar a los empleados a mejorar la calidad de los servicios ofrecidos a la ciudadanía.

\section{Productividad laboral}

En cuanto a la disponibilidad de recursos y materiales para desarrollar las actividades asignadas el 4,92\% de los servidores está totalmente en desacuerdo, el 11,48\% está en desacuerdo, el $14,75 \%$ indeciso, el $52,46 \%$ en desacuerdo y el $16,39 \%$ totalmente de acuerdo; debiendo hacer una revisión de los materiales y recursos no disponibles y que aportarían en reducir los tiempos de espera de los usuarios y posiblemente puede ser la razón por la que el 1,64\% y el 16,39\% están totalmente en desacuerdo y el 6,56\% es indiferente en relación a que pueden cumplir el trabajo asignado en menor tiempo que el planificado por sus superiores, en cambio el $39,34 \%$ y el $36,07 \%$ está de acuerdo y totalmente de acuerdo respectivamente en que logra cumplir su trabajo en menor tiempo.

\section{PROPUESTA}

El sector público debe considerar desarrollar proyectos de medición de $\mathrm{Cl}$ basados en estrategias de modernización, que permitan mejorar y plantear la administración pública basada en el conocimiento. Identificando de manera oportuna a los servidores que aportan hacia un cambio en la excelencia del servicio público. Con la finalidad de mejorar la productividad laboral de los servidores públicos de la Dirección Distrital del Ministerio de transporte y Obras Públicas del Cañar; se propone un modelo de medición del capital Intelectual mediante el empleo de indicadores de medición que permiten dar seguimiento de las actividades programadas dentro de cada uno de los procesos, además de medir el desempeño laboral. El modelo de propuesta se muestra en la figura 2 del esquema de la propuesta de esta investigación: 
Diana Alexandra González-Tenemaza; Marcos Patricio Quinteros-Cortzar; Ana Luisa del Rocio Ordoñez-Laso; Mireya Magdalena Torres-Palacios

Carta de indicador

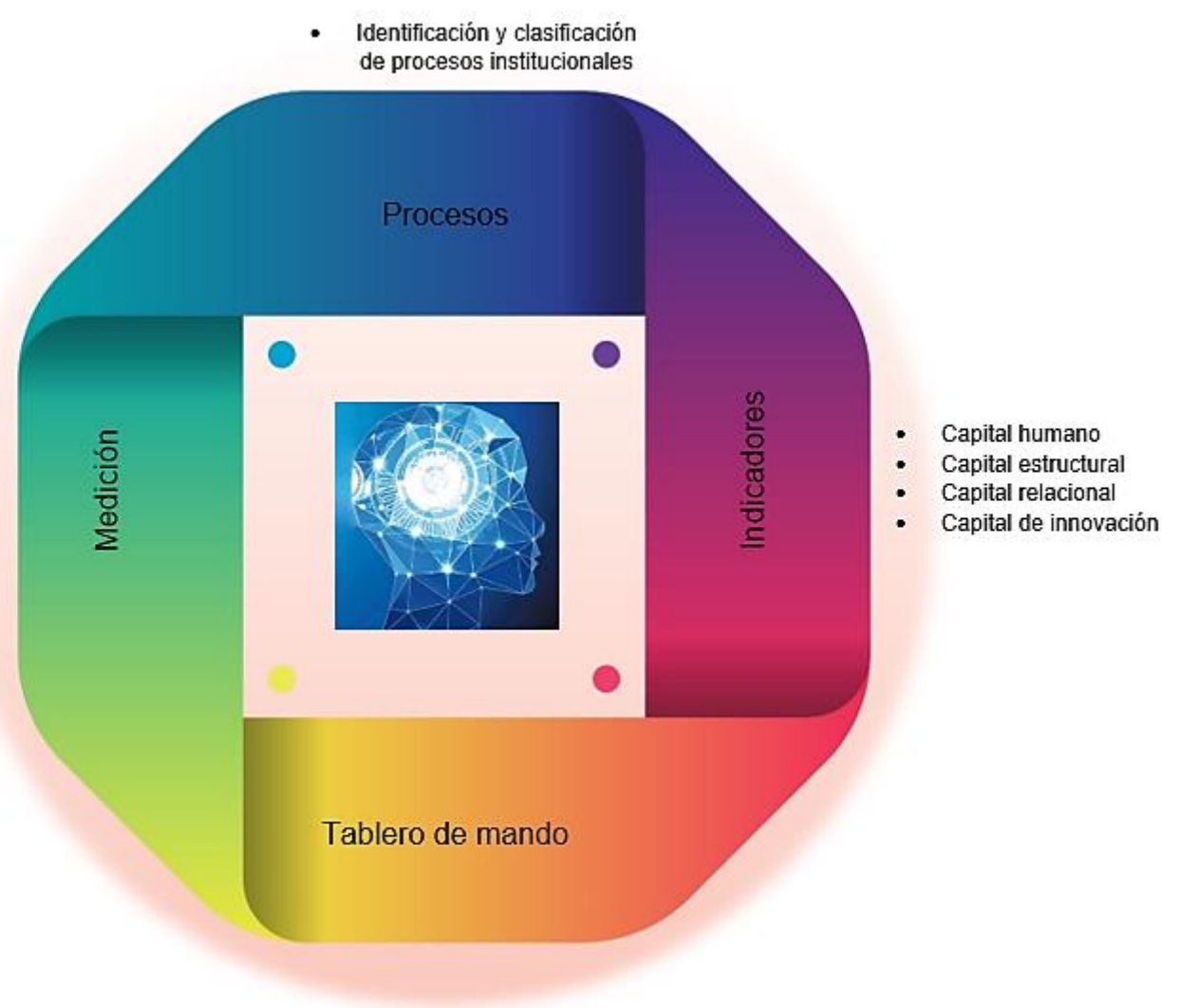

- Establecimiento de metas y límites

satisfactorio e insatisfactorio

Figura 2. Esquema de la propuesta de medición de capital intelectual. Fuente: Elaboración propia.

\section{Proceso}

Para poder gestionar adecuadamente los procesos de la Dirección Distrital del Ministerio de Transporte y Obras públicas del Cañar, se ha procedido a identificar las actividades por departamentos clasificando cada proceso en tres grupos: estratégicos, operacionales y de apoyo; definiendo además al responsable de ejecutarlo dentro de la institución. 
Diana Alexandra González-Tenemaza; Marcos Patricio Quinteros-Cortzar; Ana Luisa del Rocio Ordoñez-Laso; Mireya Magdalena Torres-Palacios

\section{Tabla 4.}

Identificación y clasificación de procesos.

\begin{tabular}{llll}
\hline No. & CLASIFICACIÓN & PROCESO & RESPONSABLE \\
\hline 1 & Estratégico & Innovación en la gestión & Director Distrital \\
2 & Estratégico & Gestión de la calidad & Director Distrital \\
3 & Operacional & Conservación vial & Jefe del departamento de Conservación vial \\
4 & Operacional & Planificación & Jefe del departamento planificación \\
5 & Operacional & Infraestructura & Jefe del departamento de Infraestructura \\
6 & Apoyo & Gestión administrativa & Coordinador administrativo financiero \\
7 & Apoyo & Gestión financiera & Analista financiero \\
8 & Apoyo & Gestión jurídica & Analista jurídico \\
9 & Apoyo & Gestión de bienes y suministros & Guardalmacén \\
10 & Apoyo & Gestión documental & Servidor encargado de Gestión documental \\
11 & Apoyo & Gestión de talento humano & Jefe de Talento Humano \\
12 & Apoyo & Gestión Tecnológica y Comunicaciones & Servidor encargado de TICS \\
\hline
\end{tabular}

Fuente: Elaboración propia.

\section{Indicadores}

Posteriormente se procedió a establecer un sistema de indicadores que involucren los procesos estratégicos, operacionales y de apoyo tomando en consideración la misión, visión y los objetivos institucionales. Posibilita en análisis de datos entre el desempeño real y el programado, mediante la evaluación de cada una de las actividades planteadas dentro de los procesos en un periodo determinado de tiempo.

El capital humano es considerado como el componente más representativo del Cl que tiene una organización, por lo tanto, se han tomado en consideración indicadores relacionados con el sentido de compromiso con la institución, así como los elementos necesarios para mantener la satisfacción laboral de los usuarios internos. El establecimiento de indicadores de capital humano permite identificar qué empleados son los que realmente contribuyen a mejorar y optimizar los procesos mediante la aplicación de los conocimientos adquiridos a lo largo de su trayectoria laboral y de las capacitaciones institucionales. 


\section{Diana Alexandra González-Tenemaza; Marcos Patricio Quinteros-Cortzar} Ana Luisa del Rocio Ordoñez-Laso; Mireya Magdalena Torres-Palacios

Dentro del Capital Estructural se ha tomado en consideración indicadores necesarios para el flujo y fácil acceso de datos de quienes lo necesiten y que además permitan identificar la necesidad de los sistemas necesarios para la gestión de la información, promoviendo la participación del personal en el aprendizaje organizativo con la finalidad de contar con herramientas de búsqueda y análisis de información que aporte a tomar decisiones, así como a fomentar un clima laboral adecuado.

Para la medición del capital relacional se proponen indicadores que favorezcan a establecer la calidad de vinculación y alianzas estratégicas con las administraciones locales y medios de comunicación, que apoyen a llevar a término los proyectos institucionales, así como a mantener un referente de comunicación con los usuarios y beneficiarios dentro de su jurisdicción. Además de establecer un eficiente manejo de proveedores que permitan tener una respuesta rápida ante los requerimientos de la institución.

Dentro del capital de innovación se plantean indicadores que contribuyan a renovar las habilidades y conocimientos, así como la inserción de nuevas tecnologías y sistemas de información que conlleve a la consecución de los objetivos institucionales, mediante la creación de nuevas ideas, retroalimentación y puesta en marcha de nuevos proyectos.

\section{Tabla 5}

Sistema de indicadores y fórmula de cálculo.

\begin{tabular}{|c|c|c|c|c|c|}
\hline No. & $\begin{array}{l}\text { Nombre del } \\
\text { indicador }\end{array}$ & $\begin{array}{l}\text { Tipo de } \\
\text { indicador }\end{array}$ & Para que sirve el indicador & Proceso & Fórmula \\
\hline 1 & $\begin{array}{l}\text { Cumplimiento de } \\
\text { obras de } \\
\text { mantenimiento y } \\
\text { conservación de } \\
\text { Infraestructuras }\end{array}$ & Efectividad & $\begin{array}{l}\text { Mide el porcentaje de } \\
\text { cumplimiento de obras de } \\
\text { mantenimiento y conservación } \\
\text { de las infraestructuras a cargo } \\
\text { de la Dirección Distrital del } \\
\text { MTOP del Cañar }\end{array}$ & Conservación vial & $\begin{array}{l}\text { \% del plan de reparación y } \\
\text { mantenimiento de la } \\
\text { infraestructura distrital } \\
\text { ejecutado }\end{array}$ \\
\hline 2 & $\begin{array}{l}\text { Cumplimiento de } \\
\text { programas de } \\
\text { mantenimiento y } \\
\text { conservación de } \\
\text { equipos y maquinaria }\end{array}$ & Efectividad & $\begin{array}{l}\text { Permite conocer el } \\
\text { cumplimiento de los programas } \\
\text { de mantenimiento y } \\
\text { conservación de equipos y } \\
\text { maquinaria }\end{array}$ & Conservación vial & $\begin{array}{l}\text { \% del plan de } \\
\text { mantenimiento y } \\
\text { conservación de equipos y } \\
\text { maquinaria ejecutado }\end{array}$ \\
\hline 3 & $\begin{array}{l}\text { Ejecución del Plan } \\
\text { Operativo Anual } \\
\text { (POA) }\end{array}$ & Efectividad & $\begin{array}{l}\text { Establece el cumplimiento del } \\
\text { POA de la Dirección Distrital } \\
\text { del MTOP del Cañar }\end{array}$ & $\begin{array}{l}\text { Gestión } \\
\text { administrativa }\end{array}$ & $\begin{array}{l}\text { \% de ejecución del Plan } \\
\text { Operativo Anual }\end{array}$ \\
\hline
\end{tabular}




\section{Diana Alexandra González-Tenemaza; Marcos Patricio Quinteros-Cortzar; Ana Luisa del Rocio Ordoñez-Laso; Mireya Magdalena Torres-Palacios}

\begin{tabular}{|c|c|c|c|c|c|}
\hline 4 & $\begin{array}{l}\text { Bienes no } \\
\text { inventariados }\end{array}$ & Eficacia & $\begin{array}{l}\text { Mide el cumplimiento en el } \\
\text { registro, control, entradas y } \\
\text { salidas de bienes en los } \\
\text { inventarios institucionales }\end{array}$ & $\begin{array}{l}\text { Gestión de bienes } \\
\text { y suministros }\end{array}$ & $\begin{array}{l}N^{\circ} \text { de bienes o suministros } \\
\text { fuera de inventarios } / \mathrm{N}^{\circ} \\
\text { total de bienes y } \\
\text { suministros en inventarios }\end{array}$ \\
\hline 5 & $\begin{array}{l}\text { Satisfacción de los } \\
\text { usuarios }\end{array}$ & Eficacia & $\begin{array}{l}\text { Mide el grado de satisfacción } \\
\text { de los usuarios }\end{array}$ & $\begin{array}{l}\text { Gestión de la } \\
\text { calidad }\end{array}$ & $\begin{array}{l}\sum_{/ T} \text { promedio por pregunta } \\
\text { preguntas realizadas }\end{array}$ \\
\hline 6 & Capacitación & Eficacia & $\begin{array}{l}\text { Mide el número de servidores } \\
\text { que pertenecen a la institución } \\
\text { que asisten a las } \\
\text { capacitaciones programadas } \\
\text { por la misma }\end{array}$ & $\begin{array}{l}\text { Gestión de talento } \\
\text { humano }\end{array}$ & $\begin{array}{l}\text { ( } N^{\circ} \text { total de servidores } \\
\text { capacitado/No total de } \\
\text { servidores) }{ }^{*} 100\end{array}$ \\
\hline 7 & Evaluación & Eficacia & $\begin{array}{l}\text { Mide el resultado del ejercicio } \\
\text { de evaluación a los servidores }\end{array}$ & $\begin{array}{l}\text { Gestión de talento } \\
\text { humano }\end{array}$ & $\begin{array}{l}\mathrm{N}^{\circ} \text { de servidores con } \\
\text { calificación mayor o igual } \\
\text { al } 90 \% / N^{\circ} \text { de servidores } \\
\text { evaluados }\end{array}$ \\
\hline 8 & $\begin{array}{l}\text { Índice de rotación del } \\
\text { personal }\end{array}$ & Eficacia & $\begin{array}{l}\text { Permite conocer la fluctuación } \\
\text { anual del personal de la } \\
\text { institución }\end{array}$ & $\begin{array}{l}\text { Gestión de talento } \\
\text { humano }\end{array}$ & $\begin{array}{l}{\left[\mathrm{N}^{\circ} \text { de desvinculaciones/ }\right.} \\
\left(\mathrm{N}^{\circ} \text { inicial de servidores }\right. \\
\left.+\mathrm{N}^{\circ} \text { final de servidores }\right) \\
/ 2] \times 100\end{array}$ \\
\hline 9 & Clima laboral & Eficacia & $\begin{array}{l}\text { Mide el nivel de satisfacción de } \\
\text { los servidores públicos en su } \\
\text { lugar de trabajo, mediante la } \\
\text { siguiente escala cualitativa de } \\
\text { calificación del ambiente } \\
\text { laboral: }(100-91=\text { excelente) } \\
\text { (81-90= bueno) }(71-80= \\
\text { regular) }\end{array}$ & $\begin{array}{l}\text { Gestión de talento } \\
\text { humano }\end{array}$ & $\begin{array}{l}\text { Sumatoria de factores de } \\
\text { clima laboral / } \mathrm{N}^{\circ} \text { total de } \\
\text { factores evaluados }\end{array}$ \\
\hline 10 & $\begin{array}{l}\text { Manejo de } \\
\text { documentación }\end{array}$ & Eficacia & $\begin{array}{l}\text { Mide el cumplimiento en el } \\
\text { registro, control, circulación y } \\
\text { organización de los } \\
\text { documentos digitales y/o físicos } \\
\text { que se envían y reciben en una } \\
\text { Institución. }\end{array}$ & $\begin{array}{l}\text { Gestión } \\
\text { documental }\end{array}$ & $\begin{array}{l}\text { No de documentos físicos } \\
\text { y/o digitales recibidos/Total } \\
\text { documentos físicos y/o } \\
\text { digitales direccionados. }\end{array}$ \\
\hline 11 & $\begin{array}{l}\text { Archivo de } \\
\text { documentación }\end{array}$ & Eficacia & $\begin{array}{l}\text { Mide el cumplimiento en el } \\
\text { registro, control, circulación y } \\
\text { organización de los } \\
\text { documentos digitales y/o físicos } \\
\text { que se envían y reciben en una } \\
\text { Institución. }\end{array}$ & $\begin{array}{l}\text { Gestión } \\
\text { documental }\end{array}$ & $\begin{array}{l}\text { No de documentos físicos } \\
\text { y/o digitales recibidos/Total } \\
\text { documentos físicos y/o } \\
\text { digitales direccionados. }\end{array}$ \\
\hline 12 & $\begin{array}{l}\text { Ejecución } \\
\text { presupuestaria }\end{array}$ & Eficacia & $\begin{array}{l}\text { Permite conocer el porcentaje } \\
\text { de ejecución presupuestaria de } \\
\text { acuerdo a lo planificado }\end{array}$ & Gestión financiera & $\begin{array}{l}\text { Monto de gasto corriente } \\
\text { devengado / Programación } \\
\text { anual de la política pública }\end{array}$ \\
\hline 13 & Pagos efectuados & Eficiencia & $\begin{array}{l}\text { Registra el cumplimiento de } \\
\text { pagos a proveedores }\end{array}$ & Gestión financiera & $\begin{array}{l}\mathrm{N}^{\circ} \text { de trámites pagados / } \\
\mathrm{N}^{\circ} \text { de trámites recibidos }\end{array}$ \\
\hline 14 & $\begin{array}{l}\text { Ejecución } \\
\text { presupuestaria }\end{array}$ & Eficacia & $\begin{array}{l}\text { permite medir la absolución de } \\
\text { consultas mediante la } \\
\text { recopilación y análisis de la } \\
\text { legislación con un plazo de } 15\end{array}$ & Gestión jurídica & $\begin{array}{l}\mathrm{N}^{\circ} \text { de criterios jurídicos } \\
\text { emitidos a tiempo / } \mathrm{N}^{\circ} \\
\text { Total de Criterios jurídicos } \\
\text { solicitados. }\end{array}$ \\
\hline
\end{tabular}




\section{Diana Alexandra González-Tenemaza; Marcos Patricio Quinteros-Cortzar; Ana Luisa del Rocio Ordoñez-Laso; Mireya Magdalena Torres-Palacios}

\begin{tabular}{|c|c|c|c|c|c|}
\hline 15 & Criterios jurídicos & Eficacia & $\begin{array}{l}\text { Permite medir la absolución de } \\
\text { consultas mediante la } \\
\text { recopilación y análisis de la } \\
\text { legislación- }\end{array}$ & Gestión jurídica & $\begin{array}{l}N^{\circ} \text { de criterios jurídicos } \\
\text { emitidos a tiempo / } \mathrm{N}^{\circ} \\
\text { Total de Criterios jurídicos } \\
\text { solicitados. }\end{array}$ \\
\hline 16 & $\begin{array}{l}\text { Atención a procesos } \\
\text { judiciales y } \\
\text { administrativos }\end{array}$ & Eficacia & $\begin{array}{l}\text { Permite conocer el porcentaje } \\
\text { de procesos judiciales y } \\
\text { administrativos atendidos. }\end{array}$ & Gestión jurídica & $\begin{array}{l}\mathrm{N}^{\circ} \text { de procesos judiciales } \mathrm{y} \\
\text { administrativos atendidos / } \\
\mathrm{N}^{\circ} \text { de procesos judiciales y } \\
\text { administrativos ingresados }\end{array}$ \\
\hline 17 & Contratación publica & Eficacia & $\begin{array}{l}\text { Este indicador mide el número } \\
\text { de contratos que se elaboran } \\
\text { dentro del tiempo establecido }\end{array}$ & Gestión jurídica & $\begin{array}{l}N^{\circ} \text { de contratos } \\
\text { elaborados/Total de } \\
\text { contratos solicitados }\end{array}$ \\
\hline 18 & $\begin{array}{l}\text { Mantenimiento de } \\
\text { equipo tecnológico }\end{array}$ & Eficiencia & $\begin{array}{l}\text { Registra el cumplimiento de } \\
\text { programas de mantenimiento } \\
\text { de equipo tecnológico. }\end{array}$ & $\begin{array}{l}\text { Gestión } \\
\text { Tecnológica y } \\
\text { Comunicaciones }\end{array}$ & $\begin{array}{l}\mathrm{N}^{\circ} \text { de equipos tecnológicos } \\
\text { a los que se ha brindado } \\
\text { mantenimiento/ } \mathrm{N}^{\circ} \text { total de } \\
\text { equipos tecnológicos }\end{array}$ \\
\hline 19 & $\begin{array}{l}\text { Solución de } \\
\text { requerimientos de } \\
\text { TICS }\end{array}$ & Eficiencia & $\begin{array}{l}\text { Refleja el número de } \\
\text { requerimientos atendidos por el } \\
\text { departamento de Tics }\end{array}$ & $\begin{array}{l}\text { Gestión } \\
\text { Tecnológica y } \\
\text { Comunicaciones }\end{array}$ & $\begin{array}{l}\mathrm{N}^{\circ} \text { de requerimientos } \\
\text { solucionados } / \mathrm{N}^{\circ} \text { total de } \\
\text { requerimientos }\end{array}$ \\
\hline 20 & $\begin{array}{l}\text { Supervisión y } \\
\text { fiscalización de } \\
\text { contratos }\end{array}$ & Eficacia & $\begin{array}{l}\text { Mide el número de contratos de } \\
\text { infraestructura supervisados y } \\
\text { fiscalizados }\end{array}$ & Infraestructura & $\begin{array}{l}N^{\circ} \text { de contratos de } \\
\text { infraestructura } \\
\text { supervisados y fiscalizados } \\
\text { /No de contratos de } \\
\text { infraestructura ejecutados }\end{array}$ \\
\hline 21 & $\begin{array}{l}\text { Índice de } \\
\text { transparencia } \\
\text { institucional }\end{array}$ & Efectividad & $\begin{array}{l}\text { Mide el nivel de transparencia } \\
\text { institucional, identificando las } \\
\text { practicas institucionales que } \\
\text { aporten a reducir los riesgos de } \\
\text { corrupción. }\end{array}$ & $\begin{array}{l}\text { Innovación en la } \\
\text { gestión }\end{array}$ & $\mathrm{N}^{\circ}$ de rendición de cuentas \\
\hline 22 & $\begin{array}{l}\text { cumplimiento de las } \\
\text { recomendaciones de } \\
\text { la Contraloría General } \\
\text { de Estado }\end{array}$ & Efectividad & $\begin{array}{l}\text { Mide el nivel de cumplimiento } \\
\text { de las recomendaciones de } \\
\text { cumplimiento obligatorio de la } \\
\text { contraloría general del estado }\end{array}$ & $\begin{array}{l}\text { Innovación en la } \\
\text { gestión }\end{array}$ & $\begin{array}{l}N^{\circ} \text { de recomendaciones } \\
\text { realizadas por la } \\
\text { Contraloría General del } \\
\text { Estado / } N^{\circ} \text { de } \\
\text { recomendaciones de la } \\
\text { Contraloría General del } \\
\text { Estado ejecutadas }\end{array}$ \\
\hline 23 & Alianzas estratégicas & Eficacia & $\begin{array}{l}\text { Permite conocer los convenios } \\
\text { y alianzas estratégicos con } \\
\text { entidades públicas o privadas }\end{array}$ & Conservación vial & $\begin{array}{l}N^{\circ} \text { de alianzas estratégicas } \\
\text { realizadas durante el año }\end{array}$ \\
\hline 24 & $\begin{array}{l}\text { Gestión de } \\
\text { requerimientos }\end{array}$ & Eficacia & $\begin{array}{l}\text { Mide el grado de gestión en la } \\
\text { atención de los requerimientos } \\
\text { de las diferentes áreas de la } \\
\text { institución }\end{array}$ & Planificación & $\begin{array}{l}\mathrm{N}^{\circ} \text { de requerimientos } \\
\text { atendidos } / \mathrm{N}^{\circ} \\
\text { requerimientos recibidos }\end{array}$ \\
\hline 25 & $\begin{array}{l}\text { Innovación } \\
\text { Tecnológica }\end{array}$ & Efectividad & $\begin{array}{l}\text { Mide la innovación de recursos } \\
\text { tecnológicos que permitan la } \\
\text { automatización y simplificación } \\
\text { de procesos }\end{array}$ & Planificación & $\begin{array}{l}\mathrm{N}^{\circ} \text { de procesos } \\
\text { automatizados } / \mathrm{N}^{\circ} \text { de } \\
\text { procesos que requieren } \\
\text { automatización }\end{array}$ \\
\hline
\end{tabular}

Fuente: Elaboración propia. 


\section{Diana Alexandra González-Tenemaza; Marcos Patricio Quinteros-Cortzar; Ana Luisa del Rocio Ordoñez-Laso; Mireya Magdalena Torres-Palacios}

Tabla 6.

Sistema de indicadores, meta y frecuencia de medición.

\begin{tabular}{|c|c|c|c|c|c|c|c|}
\hline No. & Nombre del indicador & Unidades & Meta & $\begin{array}{l}\text { Tendencia } \\
\text { esperada }\end{array}$ & $\begin{array}{l}\text { Frecuencia } \\
\text { de medición }\end{array}$ & $\begin{array}{l}\text { Fuente de } \\
\text { información }\end{array}$ & Responsable \\
\hline 1 & $\begin{array}{l}\text { Cumplimiento de obras de } \\
\text { mantenimiento y } \\
\text { conservación de } \\
\text { Infraestructuras }\end{array}$ & $\%$ & $90 \%$ & Aumentar & Mensual & $\begin{array}{l}\text { Informe del } \\
\text { Departamento de } \\
\text { Conservación }\end{array}$ & $\begin{array}{l}\text { Jefe del } \\
\text { departamento de } \\
\text { conservación }\end{array}$ \\
\hline 2 & $\begin{array}{l}\text { Cumplimiento de } \\
\text { programas de } \\
\text { mantenimiento y } \\
\text { conservación de equipos } \\
\text { y maquinaria }\end{array}$ & $\%$ & $95 \%$ & Aumentar & Mensual & $\begin{array}{l}\text { Informe del } \\
\text { Departamento de } \\
\text { Conservación }\end{array}$ & $\begin{array}{l}\text { Jefe del equipo } \\
\text { caminero }\end{array}$ \\
\hline 3 & $\begin{array}{l}\text { Ejecución del Plan } \\
\text { Operativo Anual (POA) }\end{array}$ & $\%$ & $95 \%$ & Aumentar & Anual & $\begin{array}{l}\text { Informe de } \\
\text { cumplimiento del } \\
\text { POA }\end{array}$ & $\begin{array}{l}\text { Analista } \\
\text { administrativo } \\
\text { financiero }\end{array}$ \\
\hline 4 & Bienes no inventariados & $\%$ & $10 \%$ & Reducir & Mensual & Informe & Guardalmacén \\
\hline 5 & $\begin{array}{l}\text { Satisfacción de los } \\
\text { usuarios }\end{array}$ & Número & 4.5 & Aumentar & Semestral & $\begin{array}{l}\text { Informe de } \\
\text { satisfacción }\end{array}$ & $\begin{array}{l}\text { Analista } \\
\text { Administrativo }\end{array}$ \\
\hline 6 & Capacitación & $\%$ & $95 \%$ & Aumentar & Semestral & $\begin{array}{l}\text { Informe de } \\
\text { capacitación }\end{array}$ & $\begin{array}{l}\text { Analista de Talento } \\
\text { Humano }\end{array}$ \\
\hline 7 & Evaluación & $\%$ & $90 \%$ & Aumentar & Anual & $\begin{array}{l}\text { Evaluación del } \\
\text { desempeño }\end{array}$ & $\begin{array}{l}\text { Jefes inmediatos / } \\
\text { Analista de Talento } \\
\text { Humano }\end{array}$ \\
\hline 8 & $\begin{array}{l}\text { Índice de rotación del } \\
\text { personal }\end{array}$ & $\%$ & $6 \%$ & Disminuir & Anual & $\begin{array}{l}\text { Informe de Talento } \\
\text { Humano }\end{array}$ & $\begin{array}{l}\text { Analista de Talento } \\
\text { Humano }\end{array}$ \\
\hline 9 & Clima laboral & $\%$ & $90 \%$ & Aumentar & Mensual & $\begin{array}{l}\text { Informe de } \\
\text { cumplimiento }\end{array}$ & $\begin{array}{l}\text { Servidor encargado } \\
\text { de Planificación }\end{array}$ \\
\hline 10 & $\begin{array}{l}\text { Manejo de } \\
\text { documentación }\end{array}$ & $\%$ & $95 \%$ & Aumentar & Mensual & Informe & $\begin{array}{l}\text { Servidor encargado } \\
\text { de gestión } \\
\text { documental }\end{array}$ \\
\hline 11 & $\begin{array}{l}\text { Archivo de } \\
\text { documentación }\end{array}$ & $\%$ & $95 \%$ & Aumentar & Mensual & Informe & $\begin{array}{l}\text { Servidor encargado } \\
\text { de gestión } \\
\text { documental }\end{array}$ \\
\hline 12 & Ejecución presupuestaria & $\%$ & $90 \%$ & Aumentar & Mensual & $\begin{array}{l}\text { Informe de Ejecución } \\
\text { del presupuesto }\end{array}$ & $\begin{array}{l}\text { Analista de } \\
\text { presupuesto }\end{array}$ \\
\hline 13 & Pagos efectuados & $\%$ & $90 \%$ & Aumentar & Mensual & Informe & Analista de TICS \\
\hline 14 & Ejecución presupuestaria & $\%$ & $95 \%$ & Aumentar & Mensual & Informe & Analista jurídico \\
\hline 15 & Criterios jurídicos & $\%$ & $95 \%$ & Aumentar & Mensual & Informe & Analista jurídico \\
\hline
\end{tabular}


Revista Arbitrada Interdisciplinaria KOINONIA

Año 2020. Vol V. №3. Especial: Administración

Hecho el depósito de Ley: FA2016000010

ISSN: 2542-3088

FUNDACIÓN KOINONIA (F.K). Santa Ana de Coro. Venezuela.

Diana Alexandra González-Tenemaza; Marcos Patricio Quinteros-Cortzar; Ana Luisa del Rocio Ordoñez-Laso; Mireya Magdalena Torres-Palacios

\begin{tabular}{|c|c|c|c|c|c|c|c|}
\hline 16 & $\begin{array}{l}\text { Atención a procesos } \\
\text { judiciales y } \\
\text { administrativos }\end{array}$ & $\%$ & $100 \%$ & Mantener & Mensual & Informe & Analista jurídico \\
\hline 17 & Contratación publica & $\%$ & $100 \%$ & Mantener & Mensual & Contratos & Analista jurídico \\
\hline 18 & $\begin{array}{l}\text { Mantenimiento de equipo } \\
\text { tecnológico }\end{array}$ & $\%$ & $90 \%$ & Aumentar & Semestral & Informe & Analista de TICS \\
\hline 19 & $\begin{array}{l}\text { Solución de } \\
\text { requerimientos de TICS }\end{array}$ & Horas & 2 & Disminuir & Semestral & Informe & Analista de TICS \\
\hline 20 & $\begin{array}{l}\text { Supervisión y fiscalización } \\
\text { de contratos }\end{array}$ & $\%$ & $100 \%$ & Mantener & Semestral & $\begin{array}{l}\text { Informe de } \\
\text { satisfacción }\end{array}$ & $\begin{array}{l}\text { Analista } \\
\text { Administrativo }\end{array}$ \\
\hline 21 & $\begin{array}{l}\text { Índice de transparencia } \\
\text { institucional }\end{array}$ & Unidades & 1 & Mantener & Anual & $\begin{array}{l}\text { Medios de } \\
\text { comunicación }\end{array}$ & Director distrital \\
\hline 22 & $\begin{array}{l}\text { cumplimiento de las } \\
\text { recomendaciones de la } \\
\text { Contraloría General de } \\
\text { Estado }\end{array}$ & $\%$ & $100 \%$ & Mantener & Mensual & $\begin{array}{l}\text { Informes } \\
\text { departamentales de } \\
\text { porcentaje de } \\
\text { cumplimiento }\end{array}$ & $\begin{array}{l}\text { Jefes } \\
\text { departamentales }\end{array}$ \\
\hline 23 & Alianzas estratégicas & Unidades & 3 & Aumentar & Trimestral & $\begin{array}{l}\text { Convenios y alianzas } \\
\text { estratégicas por } \\
\text { escrito. }\end{array}$ & Director distrital \\
\hline 24 & $\begin{array}{l}\text { Gestión de } \\
\text { requerimientos }\end{array}$ & $\%$ & $90 \%$ & Aumentar & Mensual & $\begin{array}{l}\text { Informe de } \\
\text { cumplimiento }\end{array}$ & $\begin{array}{l}\text { Servidor encargado } \\
\text { de Planificación }\end{array}$ \\
\hline 25 & Innovación Tecnológica & $\%$ & $80 \%$ & Aumentar & Mensual & $\begin{array}{l}\text { Informe de } \\
\text { cumplimiento }\end{array}$ & $\begin{array}{l}\text { Servidor encargado } \\
\text { de Planificación }\end{array}$ \\
\hline
\end{tabular}

Fuente: Elaboración propia. 
Diana Alexandra González-Tenemaza; Marcos Patricio Quinteros-Cortzar; Ana Luisa del Rocio Ordoñez-Laso; Mireya Magdalena Torres-Palacios

\section{Tablero de mando}

Para que la institución pueda medir y evaluar su gestión a través de indicadores, es importante plantear metas que deben ser medibles en un periodo determinado de tiempo, así como también establecer los límites satisfactorios e insatisfactorios aceptados por la institución.

\section{Tabla 7.}

Tablero de mando de indicadores.

\begin{tabular}{|c|c|c|c|c|c|}
\hline$\#$ & $\begin{array}{l}\text { Nombre del } \\
\text { indicador }\end{array}$ & Meta & Tendencia & $\begin{array}{c}\text { Límite } \\
\text { insatisfactorio }\end{array}$ & Límite satisfactorio \\
\hline 1 & $\begin{array}{l}\text { Cumplimiento de } \\
\text { obras de } \\
\text { mantenimiento y } \\
\text { conservación de } \\
\text { Infraestructuras }\end{array}$ & $90 \%$ & Aumentar & $50,0 \%$ & $87,0 \%$ \\
\hline 2 & $\begin{array}{l}\text { Cumplimiento de } \\
\text { programas de } \\
\text { mantenimiento y } \\
\text { conservación de } \\
\text { equipos y } \\
\text { maquinaria }\end{array}$ & $95 \%$ & Aumentar & $60,0 \%$ & $85,0 \%$ \\
\hline 3 & $\begin{array}{l}\text { Ejecución del Plan } \\
\text { Operativo Anual } \\
\text { (POA) }\end{array}$ & $95 \%$ & Aumentar & $85,0 \%$ & $94,0 \%$ \\
\hline 4 & $\begin{array}{l}\text { Bienes no } \\
\text { inventariados }\end{array}$ & $10 \%$ & Reducir & $9,0 \%$ & $2,0 \%$ \\
\hline 5 & $\begin{array}{l}\text { Satisfacción de los } \\
\text { usuarios }\end{array}$ & 4.5 & Aumentar & 4.0 & 4.5 \\
\hline 6 & Capacitación & $95 \%$ & Aumentar & $80,0 \%$ & $90,0 \%$ \\
\hline 7 & Evaluación & $90 \%$ & Aumentar & $80,0 \%$ & $89,0 \%$ \\
\hline 8 & $\begin{array}{l}\text { Índice de rotación } \\
\text { del personal }\end{array}$ & $6 \%$ & Disminuir & $2,0 \%$ & $5,0 \%$ \\
\hline 9 & Clima laboral & $90 \%$ & Aumentar & $70,0 \%$ & $100,0 \%$ \\
\hline 10 & $\begin{array}{l}\text { Manejo de } \\
\text { documentación }\end{array}$ & $95 \%$ & Aumentar & $70,0 \%$ & $90,0 \%$ \\
\hline 11 & $\begin{array}{l}\text { Archivo de } \\
\text { documentación }\end{array}$ & $95 \%$ & Aumentar & $70,0 \%$ & $85,0 \%$ \\
\hline 12 & $\begin{array}{l}\text { Ejecución } \\
\text { presupuestaria }\end{array}$ & $90 \%$ & Aumentar & $80,0 \%$ & $85,0 \%$ \\
\hline
\end{tabular}


Diana Alexandra González-Tenemaza; Marcos Patricio Quinteros-Cortzar; Ana Luisa del Rocio Ordoñez-Laso; Mireya Magdalena Torres-Palacios

\begin{tabular}{|c|c|c|c|c|c|}
\hline 13 & Pagos efectuados & $90 \%$ & Aumentar & $85,0 \%$ & $90,0 \%$ \\
\hline 14 & $\begin{array}{l}\text { Ejecución } \\
\text { presupuestaria }\end{array}$ & $95 \%$ & Aumentar & $80,0 \%$ & $90,0 \%$ \\
\hline 15 & Criterios jurídicos & $95 \%$ & Aumentar & $80,0 \%$ & $100,0 \%$ \\
\hline 16 & $\begin{array}{l}\text { Atención a procesos } \\
\text { judiciales y } \\
\text { administrativos }\end{array}$ & $100 \%$ & Mantener & $80,0 \%$ & $100,0 \%$ \\
\hline 17 & Contratación publica & $100 \%$ & Mantener & $85,0 \%$ & $90,0 \%$ \\
\hline 18 & $\begin{array}{l}\text { Mantenimiento de } \\
\text { equipo tecnológico }\end{array}$ & $90 \%$ & Aumentar & $85,0 \%$ & $90,0 \%$ \\
\hline 19 & $\begin{array}{l}\text { Solución de } \\
\text { requerimientos de } \\
\text { TICS }\end{array}$ & 2 & Disminuir & 1 & 2 \\
\hline 20 & $\begin{array}{l}\text { Supervisión y } \\
\text { fiscalización de } \\
\text { contratos }\end{array}$ & $100 \%$ & Mantener & $90,0 \%$ & $100,0 \%$ \\
\hline 21 & $\begin{array}{l}\text { Îndice de } \\
\text { transparencia } \\
\text { institucional }\end{array}$ & $100 \%$ & Mantener & $90,0 \%$ & $100,0 \%$ \\
\hline 22 & $\begin{array}{l}\text { cumplimiento de las } \\
\text { recomendaciones de } \\
\text { la Contraloría } \\
\text { General de Estado }\end{array}$ & $100 \%$ & Mantener & $100,0 \%$ & $100,0 \%$ \\
\hline 23 & $\begin{array}{l}\text { Alianzas } \\
\text { estratégicas }\end{array}$ & 3 & Aumentar & 1 & 5 \\
\hline 24 & $\begin{array}{l}\text { Gestión de } \\
\text { requerimientos }\end{array}$ & $90 \%$ & Aumentar & $80,0 \%$ & $100,0 \%$ \\
\hline 25 & $\begin{array}{l}\text { Innovación } \\
\text { Tecnológica }\end{array}$ & $80 \%$ & Aumentar & $80,0 \%$ & $100,0 \%$ \\
\hline
\end{tabular}

Fuente: Elaboración propia.

\section{Medición}

Finalmente, se realiza el proceso para medir y evaluar los procesos ejecutados por la Dirección Distrital del Ministerio de Transporte y Obras Públicas del Cañar mediante los indicadores establecidos mediante la presentación de cartas del indicador, donde se reflejan los logros alcanzados y la representación gráfica de los mismos; esta herramienta es fundamental para medir si el desempeño de los servidores públicos 


\section{Diana Alexandra González-Tenemaza; Marcos Patricio Quinteros-Cortzar;} Ana Luisa del Rocio Ordoñez-Laso; Mireya Magdalena Torres-Palacios

está acorde a las planificaciones departamentales, sus resultados pueden ser presentados a través de informes a los niveles directivos.

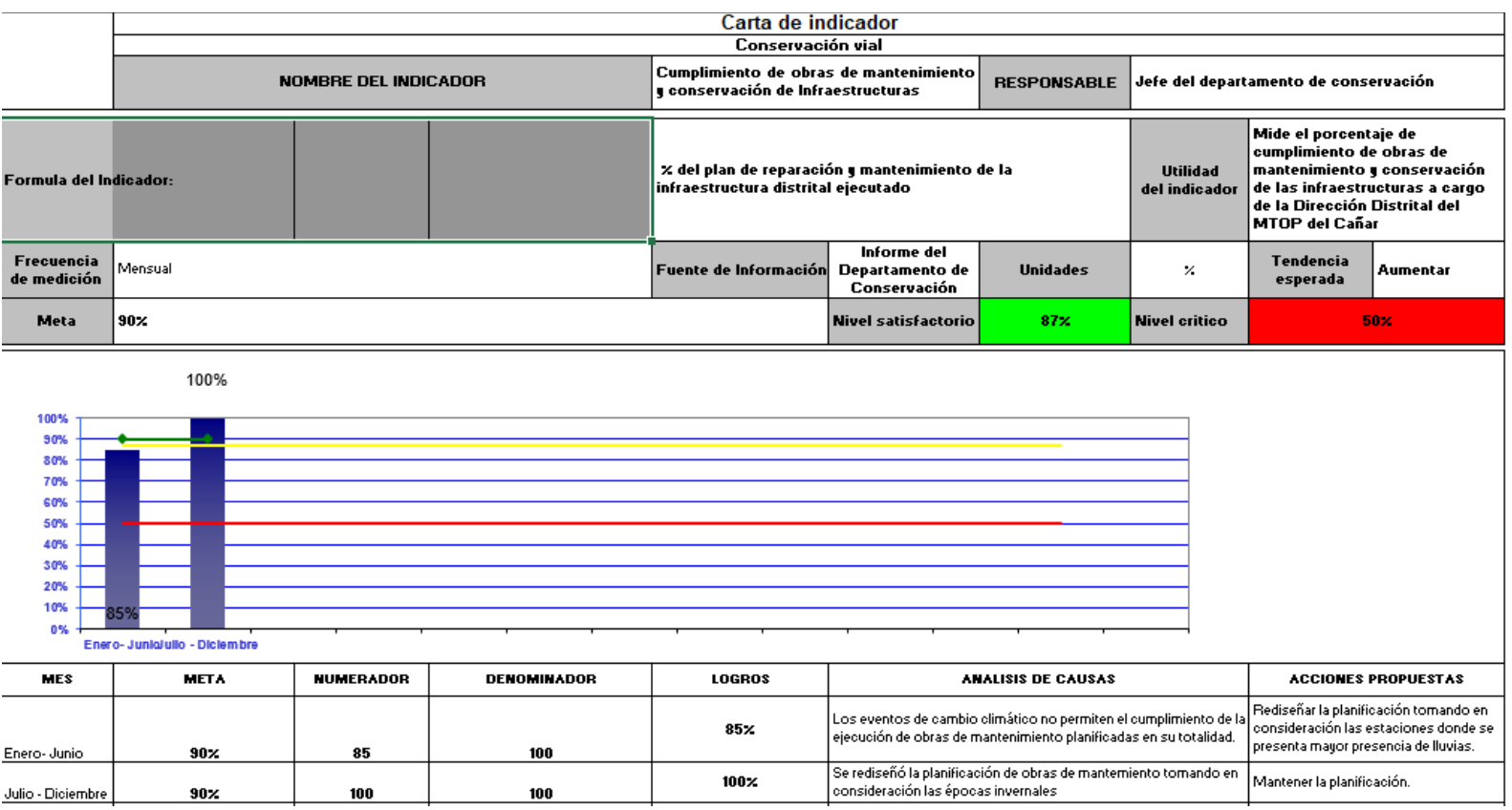

Figura 3. Diseño y presentación gráfica tomando como ejemplo el indicador 1 del sistema de medición de indicadores.

Fuente: Elaboración propia.

\section{CONCLUSIÓN}

La herramienta diseñada es fundamental para medir si el desempeño de los servidores públicos está acorde a las planificaciones departamentales, sus resultados pueden ser presentados a través de informes a los niveles directivos. Mientras que la implementación de programas de capacitación acordes a las necesidades institucionales, así como el seguimiento y fortalecimiento por parte de los directivos de la Dirección Distrital del Ministerio de Transporte y Obras públicas determinará su aplicación correcta y el aporte en la generación del conocimiento. Por otro lado, la innovación de los recursos disponibles mediante la implementación de nueva tecnología, sistematización de los procesos y constante capacitación de los servidores fortalecen la satisfacción de los usuarios y la imagen institucional a través del tiempo. 
Diana Alexandra González-Tenemaza; Marcos Patricio Quinteros-Cortzar; Ana Luisa del Rocio Ordoñez-Laso; Mireya Magdalena Torres-Palacios

\section{FINANCIAMIENTO}

No monetario.

\section{AGRADECIMIENTO}

A los servidores y trabajadores de la Dirección Distrital del Ministerio de Transporte y Obras Públicas del Cañar; por apoyar el desarrollo de la investigación.

\section{REFERENCIAS CONSULTADAS}

Arias-Pérez, J., Lozada, N., \& Henao-García, E. (2019). Gestión del Capital Intelectual y Desempeño de Grupos de Investigación Universitarios en un País Emergente. El caso de Colombia. [Intellectual Capital Management and Performance of University Research Groups in an Emerging Country, Colombia Case]. Información tecnológica, 30(4), 181188. https://dx.doi.org/10.4067/S0718-07642019000400181

Bernal, C. A. (2010). Metodología de la investigación: administración, economía, humanidades y ciencias sociales. [Research methodology: administration, economics, humanities and social sciences]. (Tercera ed.). Colombia: Pearson Educación de Colombia. Recuperado de https://n9.cl/z9jvc

Bueno, E., \& CIC. (2003). Boletín intellectus 5 [Intellectus newsletter 5]. Madrid: CICIADE (UNAM). Recuperado de https://n9.cl/blib

Bueno, E., Del Real, H., Fernandez, P., Longo, M., Merino, C., Murcia, C., \& Salmador, M. P. (2011). Modelo Intellectus de medición, gestión e información del capital intelectual. [Intellectus model for measuring, managing and reporting intellectual capital]. España: Universidad Autónoma de Madrid. Recuperado de https://n9.cl/hx9no

Bustos-Farías, E., Cerecedo-Mercado, M., \& García-González, M. (2016). Modelo de gestión de conocimiento para el desarrollo de posgrado: estudio de caso. [A Knowledge Management Model for Graduate Development: a case study]. Revista electrónica de investigación educativa, 18(1), 128-139.

Castelao-Caruana, M. (2016). Las políticas públicas y su visión de la economía social y solidaria en Argentina. [Public Policies and Their View of Social and Solidary Economy in Argentina]. Revista mexicana de ciencias políticas $y$ sociales, 61(227), 349-378. https://doi.org/10.1016/S0185-1918(16)30032-0 


\section{Diana Alexandra González-Tenemaza; Marcos Patricio Quinteros-Cortzar;} Ana Luisa del Rocio Ordoñez-Laso; Mireya Magdalena Torres-Palacios

Chiang-Vega, M., \& Ojeda-Hidalgo, J. (2013). Estudio de la relación entre satisfacción laboral y el desempeño de los trabajadores de las ferias libres. [Study of relationship between job satisfaction and workers' performance in free market fairs]. Contaduría y administración, 58(2), 39-60.

Cid, C., Báscolo, E., \& Morales, C. (2016). La eficiencia en la agenda de la estrategia de acceso y cobertura universales en salud en las Américas. [Efficiency of the agenda for universal access to health and health coverage in the Americas]. Salud Pública de México, 58(5), 496503. https://doi.org/10.21149/spm.v58i5.8182

Contreras, V., Reynaldos, K., \& Cardona, L. (2015). Clima, ambiente y satisfacción laboral: un desafío para la enfermería. [Job climate, work environment and job satisfaction: challenge for nursing]. Revista Cubana de Enfermería, 31(1), 5869.

Erazo, J. C., \& Narváez, C. I. (2020). La gestión del capital intelectual y su impacto en la efectividad organizacional de la industria de cuero y calzado en la Provincia de Tungurahua - Ecuador. [The management of intellectual capital and its impact on the ]. Revista Espacios, 41(21), 254-271.

Erazo-Álvarez, J. C., \& Narváez-Zurita, C. I. (2020). Medición y gestión del capital intelectual en la industria del cuero - calzado en Ecuador. [Measurement and management of intellectual capital in the leather industry - footwear in Ecuador]. Revista Arbitrada Interdisciplinaria Koinonía, 9(5), 437-467. http://dx.doi.org/10.35381/r.k.v5i9.662

Galleguillos-Cortés, C., Silva-Muna, J., \& Becerra-Muñoz, P. (2018). Incidencia del Capital Intelectual en el rendimiento financiero de las Universidades de Chile. [Incidence of intellectual capital in the financial performance of universities of Chile]. Ingeniare. Revista chilena de ingeniería, 26(4), 593598. https://dx.doi.org/10.4067/S0718-33052018000400593

González-Millán, J. J., \& Rodriguez-Díaz, M. T. (2016). Gestión del conocimiento, capital intelectual e indicadores aplicados [Knowledge management, intellectual capital and applied indicators] Recuperado de https://n9.cl/8ow54.

Kato, E. L. (2019). Productividad e innovación en pequeñas y medianas empresas. [Productivity and innovation in small and medium-sized companies]. Estudios Gerenciales, 35(150), $38-46$. https://doi.org/10.18046/..estger.2019.150.2909 


\section{Diana Alexandra González-Tenemaza; Marcos Patricio Quinteros-Cortzar} Ana Luisa del Rocio Ordoñez-Laso; Mireya Magdalena Torres-Palacios

Ministerio de Transporte y Obras Públicas del Ecuador (2017). MTOP 88 años al servicio de los ecuatorianos [MTOP 88 years at the service of Ecuadorians]. Súmate, revista digital interna dle Ministerio de Transporte y Obras Públicas, 8. Recuperado de: https://n9.cl/j0zqn

Monagas-Docasal, M. (2012). El capital intelectual y la gestión del conocimiento. [Intellectual capital and knowledge management]. Ingeniería Industrial, 33(2), 142-150.

Pliscoff-Varas, C. (2017). Implementando la nueva gestión pública: problemas y desafíos a la ética pública. El caso chileno. [Implementing the new public management: problems and challenges to public ethics. The Chilean case]. Convergencia, 24(73), 141-164.

Registro Oficial 18 de 08-feb-2007. Creación del Ministerio de Transporte y Obras Públicas [Creation of the Ministry of Transport and Public Works] Recuperado de https://n9.cl/mc5mc.

Registro Oficial Suplemento 294 de 06-oct.-2010. Ley Orgánica de Servicio Público, LOSEP. [Organic Law of Public Service, LOSEP]. Recuperado de https://n9.cl/4gxk3.

Reyes, P. E., Narváez, C. I., Erazo, J. C., \& Giler, L. V. (2020). Configuración del impuesto a la patente municipal con base al ingreso de las actividades económicas. Caso: GAD Municipal de Pucará - Ecuador. [Configuration of the municipal license tax based on income from economic activities. Case: Municipal GAD of Pucará - Ecuador]. Revista Espacios, 41(21), 197-211.

Robledillo-Colmenares, A, \& Velázquez-López, D. (2013). Introducción a los Sistemas de Gestión de la Calidad Total: modelo de Excelencia EFQM y Autoevaluación. [Introduction to Total Quality Management Systems: EFQM Excellence Model and self assessment]. Medicina y Seguridad del Trabajo, 59(232), 302309. https://dx.doi.org/10.4321/S0465-546X2013000300002

Rodríguez Combeller, C. (1999). El nuevo escenario: La cultura de calidad y productividad en las empresas. [The new scenario: The culture of quality and productivity in companies]. Recuperado de: https://n9.cl/dbkv. México: ITESO

Rodríguez, D., Erazo, J., \& Narváez, C. (2019). Técnicas cuantitativas de investigación de mercados aplicadas al consumo de carne en la generación millennial de la ciudad de Cuenca (Ecuador) [Quantitative market research techniques applied to meat consumption in the millennial generation of the city of Cuenca (Ecuador)]. [Quantitative market research techniques] Revista Espacios, 40(32), 20. 
Diana Alexandra González-Tenemaza; Marcos Patricio Quinteros-Cortzar; Ana Luisa del Rocio Ordoñez-Laso; Mireya Magdalena Torres-Palacios

Van-den-Berghe, E. (2015). Diseñe y administre su propia empresa: Proyectándola a los TLC de Estados Unidos, Suiza y Canadá. [Design and manage your own company: Projecting it to the FTAs of the United States, Switzerland and Canada]. (Cuarta edición ed.). Bogotá: Ecoe Ediciones. Recuperado de https://n9.cl/ib2z7

Villegas-González, E., Hernández-Calzada, M., \& Salazar-Hernández, B. (2017). La medición del capital intelectual y su impacto en el rendimiento financiero en empresas del sector industrial en México. [Mexico's industrial sector companies: A measurement of intellectual capital and its impact on financial performance]. Contaduría y administración, 62(1), 184206. https://doi.org/10.1016/j.cya.2016.10.002

Villegas-González, E., Salazar-Hernández, B. C., \& Hernández-Calzada, M. A. (2017). La medición del capital intelectual y su impacto en el rendimiento financiero en empresas del sector industrial en México [The measurement of intellectual capital and its impact on financial performance in companies in the industrial sector in Mexico]. Contaduría y Administración, 62(1), 184-206. https://doi.org/10.1016/j.cya.2016.10.002 